\title{
Investigation into the Effective Chemical Structure of Metal-Containing Ionic Liquids for Oxygen Absorption
}

Atsushi Matsuoka, Eiji Kamio, and Hideto Matsuyama*

Research Center for Membrane and Film Technology and Department of Chemical Science and

Engineering, Kobe University, 1-1 Rokkodai-cho, Nada-ku, Kobe, Hyogo 657-8501, Japan.

\section{Supporting Information}

Table of contents

(1) Synthesis and characterization of the IL ligands

(2) FT-IR spectra of the synthesized MCILs

(3) Gas absorption apparatus

(4) Confirmation of the removal of ethanol from the MCILs used for gas absorption test

(5) Changes in the UV absorption spectra of the MCILs during the complex-formation reaction between $\mathrm{O}_{2}$ and the MCIL in methanol

(6) The ratio of com 1 and com 2 of the $\mathrm{O}_{2}-\mathrm{MCIL}$ complex in the MCIL/methanol mixture at the equilibrium state

(7) Measurement of the molar absorption coefficients

(8) $\mathrm{O}_{2}$ absorption isotherms of $\left[\mathrm{P}_{\mathrm{nnnm}}\right]_{2}\left[\mathrm{Co}(\right.$ salen $\left.)(N-\mathrm{mGly})_{2}\right]$ and $\left[\mathrm{P}_{\mathrm{nnnm}}\right]_{2}[\mathrm{Co}($ salen $)(N-$ $\left.\mathrm{mGly})\left(\mathrm{Tf}_{2} \mathrm{~N}\right)\right]$ with the unit of $\mathrm{mol}-\mathrm{O}_{2} / \mathrm{mol}-\mathrm{MCIL}$

References 


\section{(1) Synthesis and characterization of the IL ligands.}

\section{Synthesis of triethylbutylphosphonium bromide $\left(\left[\mathrm{P}_{2225}\right][\mathrm{Br}]\right)$}

Triethylbutylphosphonium bromide $\left(\left[\mathrm{P}_{2225}\right][\mathrm{Br}]\right)$ was synthesized according to the method reported elsewhere, ${ }^{1}$ as a source material for the synthesis of $\left[\mathrm{P}_{2225}\right][\mathrm{N}-\mathrm{mGly}]$ and $\left[\mathrm{P}_{2225}\right]\left[\mathrm{Tf}_{2} \mathrm{~N}\right]$. A portion $(0.1 \mathrm{~mol})$ of 1-bromopentane was reacted with $0.1 \mathrm{~mol}$ of triethylphosphine $\left(1.0 \mathrm{~mol} / \mathrm{dm}^{3}\right.$ in THF) under reflux at $353 \mathrm{~K}$ for $6 \mathrm{~h}$. Subsequently, the mixture was evaporated to remove THF and unreacted 1-bromopentane; Triethylbutylphosphonium bromide $\left[\mathrm{P}_{2225}\right][\mathrm{Br}]$ was obtained as a white hygroscopic solid.

\section{Synthesis of $\left[\mathbf{P}_{\text {nnnm }}\right][N-m G l y]$}

$\left[\mathrm{P}_{\mathrm{nnnm}}\right][N-\mathrm{mGly}]$ was synthesized by a normalization reaction. First, $\left[\mathrm{P}_{\mathrm{nnnm}}\right][\mathrm{Br}](0.020 \mathrm{~mol})$ was dissolved in a solvent $\left(50 \mathrm{~cm}^{3}\right)$. As solvents, ethanol was used with $\left[\mathrm{P}_{66614}\right][\mathrm{Br}]$ and Milli-Q water was used with $\left[\mathrm{P}_{4448}\right][\mathrm{Br}]$ and $\left[\mathrm{P}_{2225}\right][\mathrm{Br}]$. Afterward, $\mathrm{OH}$-form anion exchange resin $(40 \mathrm{~g})$ was added to the $\left[\mathrm{P}_{\mathrm{nnnm}}\right][\mathrm{Br}]$ solution and stirred for $12 \mathrm{~h}$. After removing the resin by filtration, $N$-mGly $(0.020$ mol) was added to the filtrate and stirred for $6 \mathrm{~h}$. By evaporating the mixture at $323 \mathrm{~K}$ for $5 \mathrm{~h}$, $\left[\mathrm{P}_{\mathrm{nnnm}}\right]\left[\mathrm{N}\right.$-mGly] was obtained in a liquid form. The product was analyzed by ${ }^{1} \mathrm{H}$ NMR spectroscopy (Bruker Advance 500, Bruker BioSpin). The chemical structure and assigned chemical shifts of each $\left[\mathrm{P}_{\mathrm{nnnm}}\right][N-\mathrm{mGly}]$ are shown in Figure $\mathrm{S} 1$. 
(a)

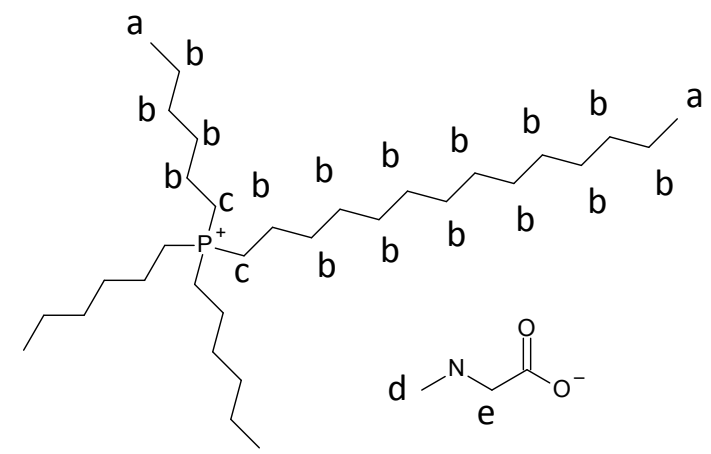

trihexyltetradecylphosphsonium $N$-methylglycinate $\left(\left[\mathrm{P}_{66614}\right][\mathrm{N}\right.$-mGly])

$1 \mathrm{H}$ NMR (d6-DMSO, $\delta / \mathrm{ppm}$ relative to TMS): $\delta=0.78-0.86$ (m, $12 \mathrm{H} ; \mathrm{a}), 1.15-1.47(\mathrm{~m}, 48 \mathrm{H} ; \mathrm{b}), 2.09-2.19(\mathrm{~m}, 8 \mathrm{H} ; \mathrm{c}), 2.46(\mathrm{~s}$, $3 \mathrm{H} ; \mathrm{d}), 2.55$ (s, $2 \mathrm{H} ; \mathrm{e})$

(b)

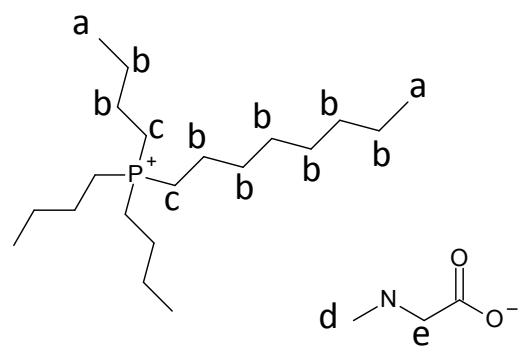

tributyloctylphosphsonium $N$-methylglycinate $\left(\left[\mathrm{P}_{4448}\right][\mathrm{N}\right.$-mGly])

$1 \mathrm{H}$ NMR (d6-DMSO, $\delta / p p m$ relative to TMS): $\delta=0.81-0.94$ (m, $12 \mathrm{H} ; \mathrm{a}), 1.21-1.52(\mathrm{~m}, 24 \mathrm{H} ; \mathrm{b}), 2.14-2.21(\mathrm{~m}, 8 \mathrm{H} ; \mathrm{c}), 2.24(\mathrm{~s}, 3 \mathrm{H}$; d), $2.68(\mathrm{~s}, 2 \mathrm{H} ; \mathrm{e})$

(c)<smiles>[2H]C[B]CC[P+](CC)(CC)CC</smiles>

triethylpentylphosphsonium $\mathrm{N}$-methylglycinate $\left(\left[\mathrm{P}_{2225}\right][\mathrm{N}-\mathrm{mGly}]\right)$

$1 \mathrm{H}$ NMR (d6-DMSO, $\delta / \mathrm{ppm}$ relative to TMS): $\delta=0.81-1.12(\mathrm{~m}$, $12 \mathrm{H} ; \mathrm{a}), 1.24-1.58(\mathrm{~m}, 6 \mathrm{H} ; \mathrm{b}), 2.12-2.22(\mathrm{~m}, 8 \mathrm{H} ; \mathrm{c}), 2.24(\mathrm{~s}, 3 \mathrm{H}$; d), $2.66(\mathrm{~s}, 2 \mathrm{H} ; \mathrm{e})$

Figure S1. Chemical structures of (a) $\left[\mathrm{P}_{66614}\right][N-\mathrm{mGly}]$, (b) $\left[\mathrm{P}_{4448}\right][N-\mathrm{mGly}]$, and (C) $\left[\mathrm{P}_{2225}\right][N-\mathrm{mGly}]$, including ${ }^{1} \mathrm{H}$ NMR results. 


\section{Synthesis of $\left[P_{n n n m}\right]\left[\mathbf{T f}_{2} N\right]$}

$\left[\mathrm{P}_{n n n m}\right]\left[\mathrm{Tf}_{2} \mathrm{~N}\right]$ was synthesized by the anion-exchange reaction of $\left[\mathrm{P}_{\mathrm{nnnm}}\right][\mathrm{Br}]$ with $\mathrm{LiTf}_{2} \mathrm{~N}$. A certain amount of $\operatorname{LiTf}_{2} \mathrm{~N}(0.020 \mathrm{~mol})$ was added to the $\left[\mathrm{P}_{\mathrm{nnnm}}\right][\mathrm{Br}] / \mathrm{H}_{2} \mathrm{O}$ mixture containing $0.02 \mathrm{~mol}$ $\left[\mathrm{P}_{\mathrm{nnnm}}\right][\mathrm{Br}]$ and vigorously agitated for $2 \mathrm{~h}$. After $2 \mathrm{~h}$, the water phase was removed by decantation, and the residual IL phase was washed with Milli-Q water three times. Subsequently, the IL phase was dried by evaporation at $333 \mathrm{~K}$ for $6 \mathrm{~h}$. Each $\left[\mathrm{P}_{\mathrm{nnnm}}\right]\left[\mathrm{Tf}_{2} \mathrm{~N}\right]$ was obtained as a transparent liquid. 


\section{(2) FT-IR spectra of the synthesized MCILs}

The synthesized MCILs $\left(\left[\mathrm{P}_{\mathrm{nnnm}}\right]_{2}\left[\mathrm{Co}(\mathrm{salen})(N-\mathrm{mGly})_{2}\right] \quad\right.$ and $\quad\left[\mathrm{P}_{\mathrm{nnnm}}\right]_{2}[\mathrm{Co}(\mathrm{salen})(N-$ mGly) $\left.\left(\mathrm{Tf}_{2} \mathrm{~N}\right)\right]$ ) were dried in vacuo at $373 \mathrm{~K}$ for $12 \mathrm{~h}$; thereafter, the FT-IR spectra of these MCILs were recorded (FT-IR Spectrometer, NIKOLET iS5 with id5 ATR accessory, Thermo Fisher Scientific). The FT-IR absorption spectra of the synthesized MCILs are shown in Figure S2. The assigned peaks of the FT-IR absorption spectra of the synthesized MCILs are listed in Table S1. The observed FT-IR absorption spectra were almost identical to the previously reported spectra. ${ }^{2}$ Moreover, no peak indicative of any residual ethanol, which was used as the solvent for synthesis, was observed. Therefore, all the MCILs were synthesized successfully. 
(a)

- $\left[\mathrm{P}_{2225}\right]_{2}\left[\mathrm{Co}(\right.$ salen $\left.)(\mathrm{N}-\mathrm{mGly})_{2}\right]$

- $\left.\left[\mathrm{P}_{4448}\right]_{2}[\mathrm{Co} \text { (salen)(N-mGly })_{2}\right]$

- $\left.\left[\mathrm{P}_{66614}\right]_{2}[\mathrm{Co} \text { (salen)(N-mGly) })_{2}\right]$

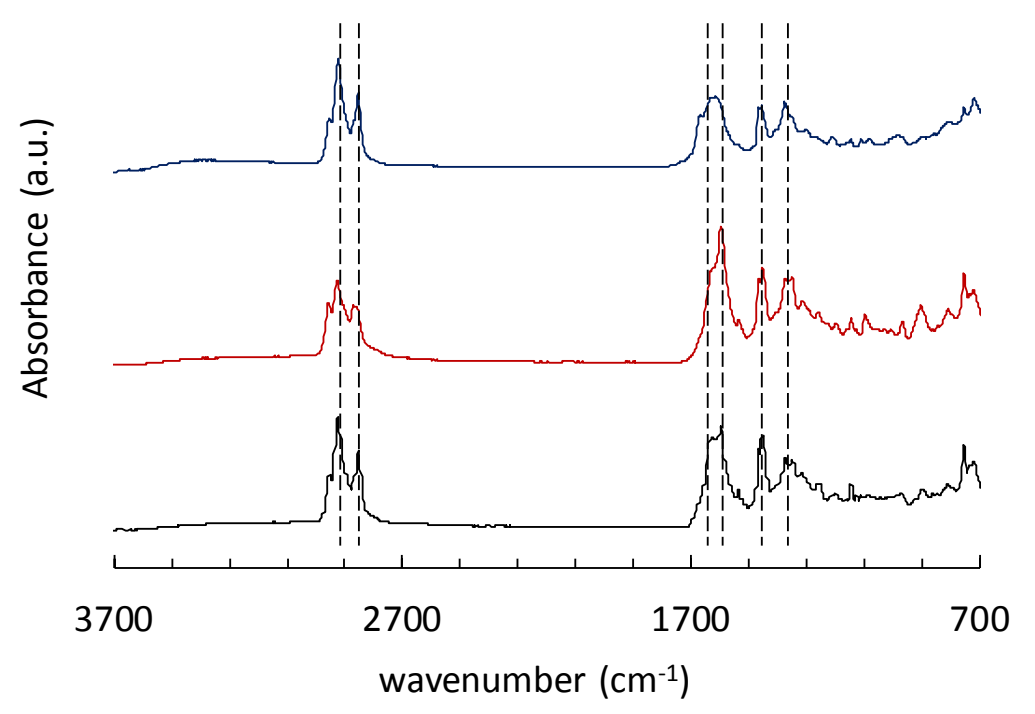

(b) $\quad-\left[\mathrm{P}_{2225}\right]_{2}\left[\mathrm{Co}(\right.$ salen $\left.)(\mathrm{N}-\mathrm{mGly})\left(\mathrm{Tf}_{2} \mathrm{~N}\right)\right]$

- $\left[\mathrm{P}_{4448}\right]_{2}\left[\mathrm{Co}(\right.$ salen $\left.)(\mathrm{N}-\mathrm{mGly})\left(\mathrm{Tf}_{2} \mathrm{~N}\right)\right]$

- $\left[\mathrm{P}_{66614}\right]_{2}\left[\mathrm{Co}(\right.$ salen $\left.)(\mathrm{N}-\mathrm{mGly})\left(\mathrm{Tf}_{2} \mathrm{~N}\right)\right]$

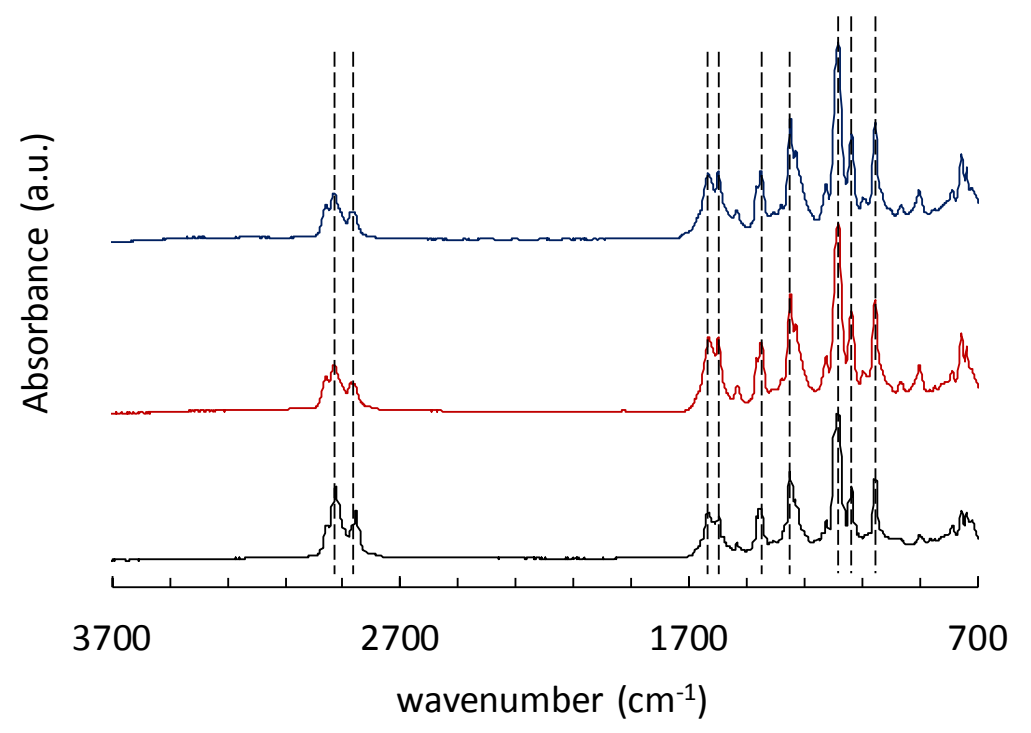

Figure S2. FT-IR spectra of the synthesized (a) $\left[\mathrm{P}_{\text {nnnm }}\right]_{2}\left[\mathrm{Co}\right.$ (salen) $\left(N-\mathrm{mGly}_{2}\right]$ and (b) $\left[\mathrm{P}_{\mathrm{nnnm}}\right]_{2}\left[\mathrm{Co}(\right.$ salen $)\left(\mathrm{N}\right.$-mGly) $\left.\left(\mathrm{Tf}_{2} \mathrm{~N}\right)\right]$ MCILs. 
Table S1. Assignments of the FT-IR absorption spectra of the synthesized $\left[\mathrm{P}_{\mathrm{nnnm}}\right]_{2}[\mathrm{Co}(\mathrm{salen})(\mathrm{N}-$

mGly $\left.)_{2}\right]$ and $\left[\mathrm{P}_{\mathrm{nnnm}}\right]_{2}\left[\mathrm{Co}(\right.$ salen $\left.)(N-\mathrm{mGly})\left(\mathrm{Tf}_{2} \mathrm{~N}\right)\right]$ MCILs. $^{2}$

\begin{tabular}{ccc}
\hline \multicolumn{2}{c}{ Wavenumber $\left(\mathrm{cm}^{-1}\right)$} & \\
\cline { 1 - 2 }$\left[\mathrm{P}_{\mathrm{nnnm}}\right]_{2}\left[\mathrm{Co}(\mathrm{salen})(N-\mathrm{mGly})_{2}\right]$ & $\begin{array}{c}{\left[\mathrm{P}_{\mathrm{nnnm}}\right]_{2}[\mathrm{Co}(\text { salen })(N-} \\
\left.\mathrm{mGly})\left(\mathrm{Tf}_{2} \mathrm{~N}\right)\right]\end{array}$ & Assignment \\
\hline 2920 & 2920 & $-\mathrm{CH}_{2}-$ symmetric stretching \\
2850 & 2850 & $-\mathrm{CH}_{3}$ symmetric stretching \\
1635 & 1635 & $-\mathrm{C}=\mathrm{N}$ - stretching \\
1600 & 1600 & $-\mathrm{COO}^{-}$asymmetric stretching \\
1470 & 1470 & $-\mathrm{CH}_{3}$ degeneracy bending \\
1380 & 1380 & $-\mathrm{NH}$ wagging \\
& 1180 & $-\mathrm{CF}_{3}$ asymmetric stretching \\
& 1140 & $-\mathrm{SO}_{2}$ symmetric stretching \\
& 1060 & $\mathrm{~S}_{-}-\mathrm{N}-\mathrm{S}$ symmetric stretching \\
\hline
\end{tabular}


(3) Gas absorption apparatus

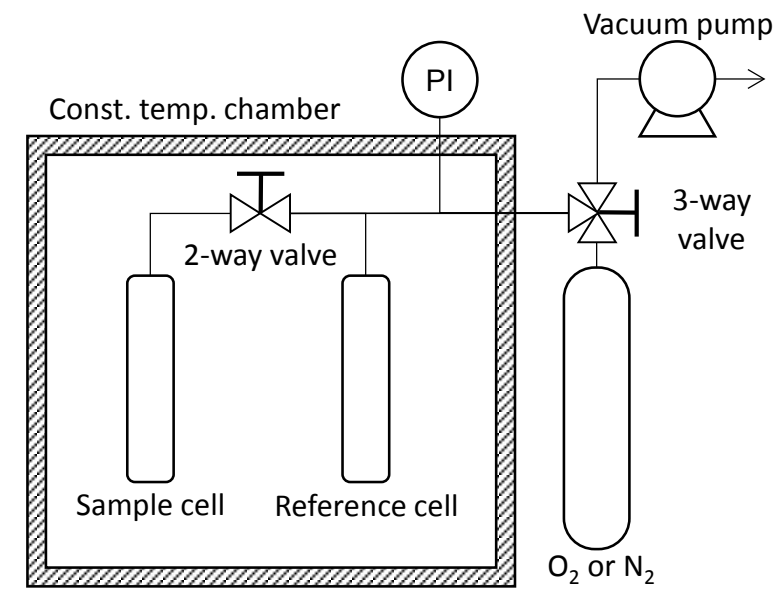

Figure S3. Schematic of the apparatus used for the gas absorption tests 


\section{(4) Confirmation of the removal of ethanol from the MCILs used for}

\section{the gas absorption tests}

Figure S4 shows the typical examples of the FT-IR spectra of the MCILs after completion of the gas absorption test and the MCIL/ethanol solution. For the spectra of the MCIL/ethanol solution, strong peaks indicative of ethanol and weak peaks indicative of the MCIL were observed for both of the $\left[\mathrm{P}_{4448}\right]_{2}\left[\mathrm{Co}(\right.$ salen $)\left(N-\mathrm{mGly}_{2}\right]$ and $\left[\mathrm{P}_{4448}\right]_{2}\left[\mathrm{Co}(\right.$ salen $\left.)(N-\mathrm{mGly})\left(\mathrm{Tf}_{2} \mathrm{~N}\right)\right]$ systems. Conversely, for the spectra of the sample after completion of the gas absorption test, no peaks indicative of ethanol were observed, and the spectra were almost similar to those of the neat MCILs (Figure S2) for both of the $\left[\mathrm{P}_{4448}\right]_{2}\left[\mathrm{Co}(\right.$ salen $\left.)(N-\mathrm{mGly})_{2}\right]$ and $\left[\mathrm{P}_{4448}\right]_{2}\left[\mathrm{Co}(\right.$ salen $\left.)(N-\mathrm{mGly})\left(\mathrm{Tf}_{2} \mathrm{~N}\right)\right]$ systems. These results indicated that ethanol was eliminated from the MCILs, which was used for the gas absorption test. 
(a)

The sample after the gas absorption test

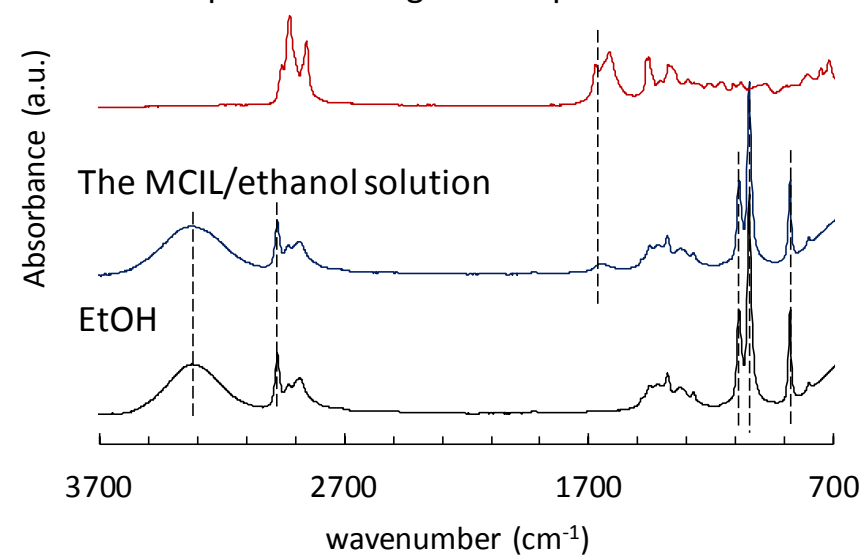

(b)

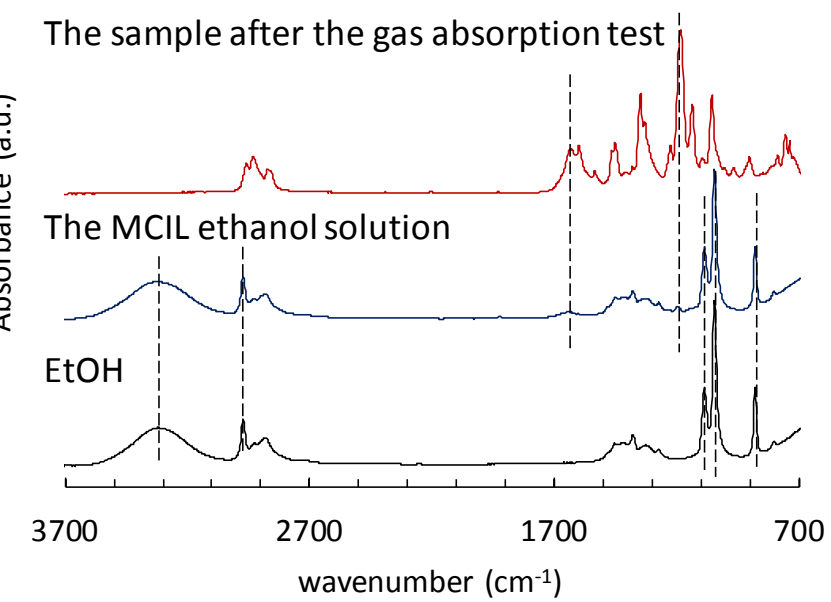

Figure S4. FT-IR spectra of the MCIL/ethanol solution and the MCIL after completion of the tests for

(a) $\left[\mathrm{P}_{4448}\right]_{2}\left[\mathrm{Co}(\right.$ salen $\left.)(N-\mathrm{mGly})_{2}\right]$ and (b) $\left[\mathrm{P}_{4448}\right]_{2}\left[\mathrm{Co}(\right.$ salen $)(N$-mGly $\left.)\left(\mathrm{Tf}_{2} \mathrm{~N}\right)\right]$ systems. 
(5) Changes in the UV absorption spectra of the MCILs during the

\section{complex-formation reaction between $\mathrm{O}_{2}$ and the MCIL in methanol}
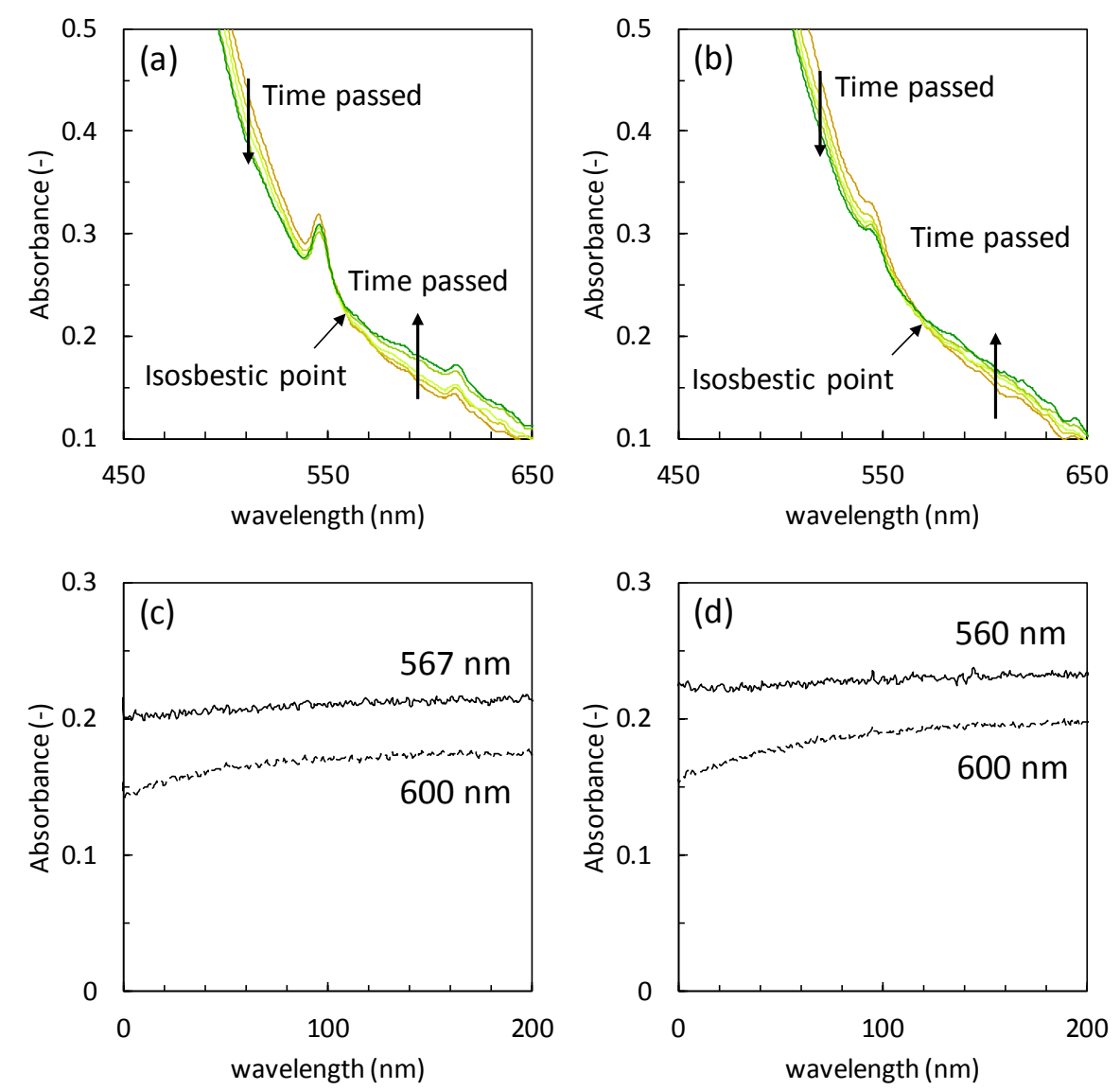

Figure S5. Changes in the UV absorption spectra of (a) $\left[\mathrm{P}_{66614}\right]_{2}\left[\mathrm{Co}(\right.$ salen $\left.)(N-\mathrm{mGly})_{2}\right]$ and (b)

$\left[\mathrm{P}_{66614}\right]_{2}\left[\mathrm{Co}(\right.$ salen $\left.)(N-m G l y)\left(\mathrm{Tf}_{2} \mathrm{~N}\right)\right]$, and time courses of the absorbance of $(\mathrm{c})\left[\mathrm{P}_{66614}\right]_{2}[\mathrm{Co}($ salen $)(\mathrm{N}-$

mGly $\left.)_{2}\right]$ and (d) $\left[\mathrm{P}_{66614}\right]_{2}\left[\mathrm{Co}(\right.$ salen $\left.)(N-\mathrm{mGly})\left(\mathrm{Tf}_{2} \mathrm{~N}\right)\right]$ during the complex-formation reaction between

$\mathrm{O}_{2}$ and the MCIL in methanol $\left(p_{\mathrm{O} 2}=5 \mathrm{kPa}, T=298 \mathrm{~K}\right)$ at fixed wavelengths. 

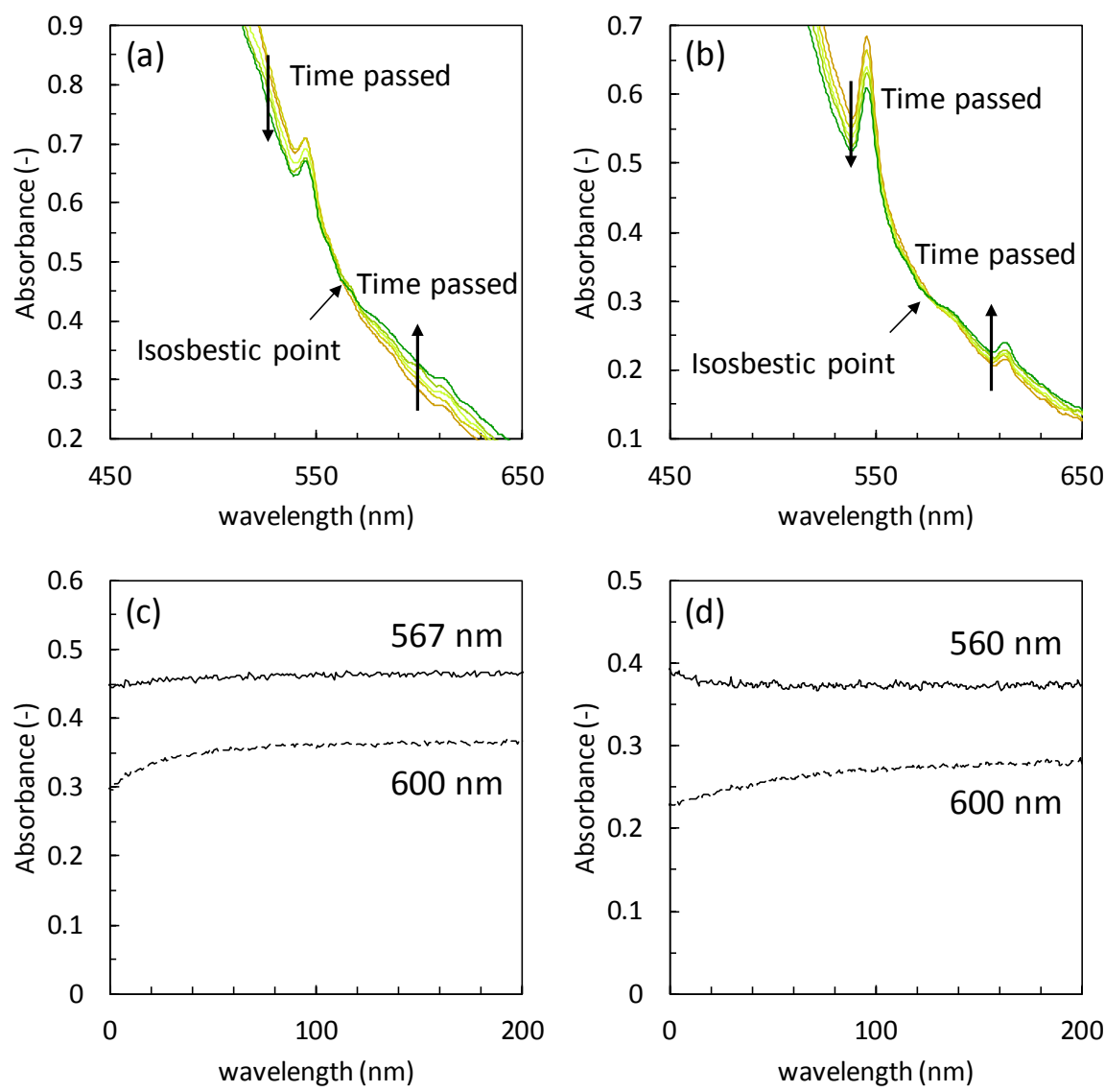

Figure S6. Changes in the UV absorption spectra of (a) $\left[\mathrm{P}_{2225}\right]_{2}\left[\mathrm{Co}(\right.$ salen $\left.)(N-\mathrm{mGly})_{2}\right]$ and (b)

$\left[\mathrm{P}_{2225}\right]_{2}\left[\mathrm{Co}(\right.$ salen $)(\mathrm{N}$-mGly $\left.)\left(\mathrm{Tf}_{2} \mathrm{~N}\right)\right]$, and time courses of the absorbance of $(\mathrm{c})\left[\mathrm{P}_{2225}\right]_{2}[\mathrm{Co}(\mathrm{salen})(\mathrm{N}-$ mGly $\left.)_{2}\right]$ and (d) $\left[\mathrm{P}_{2225}\right]_{2}\left[\mathrm{Co}(\right.$ salen $\left.)(N-\mathrm{mGly})\left(\mathrm{Tf}_{2} \mathrm{~N}\right)\right]$ during the complex-formation reaction between $\mathrm{O}_{2}$ and the MCIL in methanol $\left(p_{\mathrm{O} 2}=5 \mathrm{kPa}, T=298 \mathrm{~K}\right)$ at fixed wavelengths. 
(6) The ratio of com1 and com2 of the $\mathrm{O}_{2}-$ MCIL complex in the

\section{MCIL/methanol mixture at the equilibrium state}
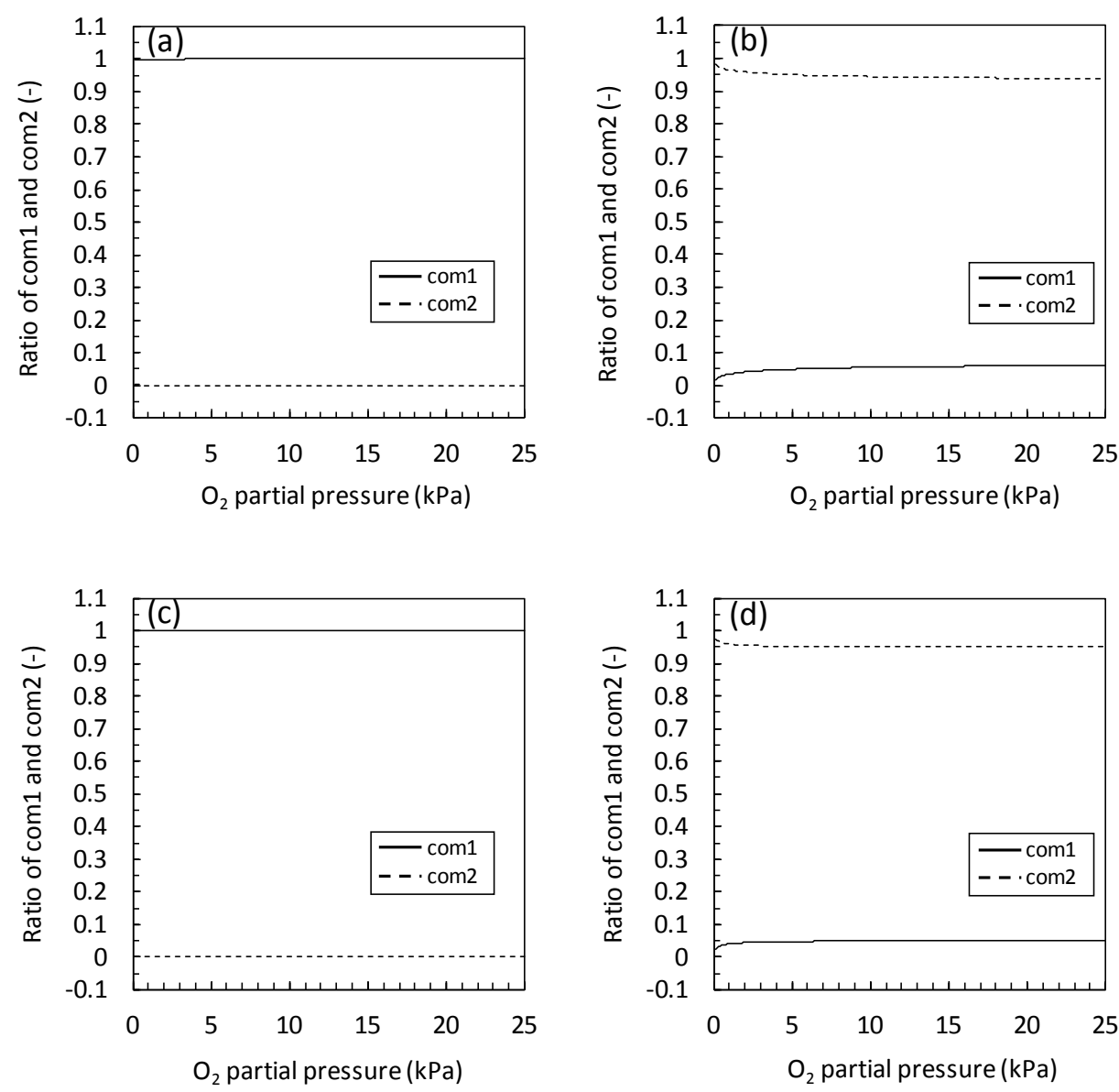

Figure S7. Ratio of com 1 and com2 of the $\mathrm{O}_{2}-\mathrm{MCIL}$ complex in the MCIL/methanol mixture at equilibrium state while in contact with the $\mathrm{O}_{2} / \mathrm{N}_{2}$ mixture with various $\mathrm{O}_{2}$ partial pressures. (a) $\left[\mathrm{P}_{66614}\right]_{2}\left[\mathrm{Co}(\right.$ salen$)\left(N-\mathrm{mGly}_{2}\right], \quad$ (b) $\left[\mathrm{P}_{66614}\right]_{2}\left[\mathrm{Co}(\right.$ salen $\left.)(N-\mathrm{mGly})\left(\mathrm{Tf}_{2} \mathrm{~N}\right)\right], \quad$ (c) $\left[\mathrm{P}_{2225}\right]_{2}[\mathrm{Co}(\mathrm{salen})(N-$ mGly $\left.)_{2}\right]$, and (d) $\left[\mathrm{P}_{2225}\right]_{2}\left[\mathrm{Co}(\right.$ salen $\left.)(N-\mathrm{mGly})\left(\mathrm{Tf}_{2} \mathrm{~N}\right)\right]$. 


\section{(7) Measurement of molar absorption coefficients}

For all experiments, the same apparatus described in 2.3 was used, and each MCIL was dried in vacuo at $373 \mathrm{~K}$ for $12 \mathrm{~h}$ prior to the experiment.

First, the molar absorption coefficients at the isosbestic point $\left(\varepsilon_{\text {iso }}\right)$ of each MCIL were measured. MCIL/methanol solutions with different MCIL concentrations were prepared for each MCIL. The absorbance of these MCIL/methanol solutions was measured using a UV probe at $298 \mathrm{~K}$. After the absorbance measurements, calibration curves, shown in Figure S8(a), were prepared for each MCIL. The $\varepsilon_{\text {iso }}$ value of each MCIL was determined by the slope of each calibration curve.

The molar absorption coefficients of the neat MCIL at $600 \mathrm{~nm}\left(\varepsilon_{\mathrm{MCIL}, 600}\right)$ were measured under a $\mathrm{N}_{2}$ atmosphere. Methanol $\left(80 \mathrm{~cm}^{3}\right)$ was poured into a three-neck glass flask. After that, $\mathrm{N}_{2}$ was passed through the flask for $6 \mathrm{~h}$ to replace the system gas with $\mathrm{N}_{2}$. Conversely, to prepare the methanol solutions of the MCIL, a certain amount of methanol, from which $\mathrm{O}_{2}$ had been removed by $\mathrm{N}_{2}$ bubbling, was added to the degassed MCIL. MCIL/methanol solutions with five different MCIL concentrations were prepared. The prepared MCIL/methanol solution was added to the degassed methanol in the flask through the septum using a syringe. After 30 min of stirring, the absorbance measurements of the methanol solution in the flask at $600 \mathrm{~nm}\left(A_{600}\right)$ and isosbestic point $\left(A_{\text {iso }}\right)$ were conducted using the UV probe at $298 \mathrm{~K}$. After the absorbance measurements, the concentration of the solution was calculated from $A_{\text {iso }}$ and $\varepsilon_{\text {iso }}$ using eq. 15 for $\left.\left[\mathrm{P}_{\text {nnnm }}\right]_{2}[\mathrm{Co} \text { (salen)(N-mGly })_{2}\right]$ and eq. 17 for 
$\left[\mathrm{P}_{\mathrm{nnnm}}\right]_{2}\left[\mathrm{Co}\right.$ (salen) $\left(N\right.$-mGly) $\left.\left(\mathrm{Tf}_{2} \mathrm{~N}\right)\right]$ under the condition that $C_{\text {com1 }}$ and $C_{\text {com2 } 2}$ were 0 . The calibration curves shown in Figure S8(b) were prepared for each MCIL, after which $\varepsilon_{\mathrm{MCIL}, 600}$ values were determined by the slope of each calibration curve.

Finally, the molar absorption coefficient of com1 for $\left[\mathrm{P}_{\mathrm{nnnm}}\right]_{2}\left[\mathrm{Co}(\mathrm{salen})(\mathrm{N}-\mathrm{mGly})_{2}\right]$ at $600 \mathrm{~nm}$ $\left(\varepsilon_{\mathrm{com} 1,600}\right)$ and that of com2 for $\left[\mathrm{P}_{\mathrm{nnnm}}\right]_{2}\left[\mathrm{Co}(\mathrm{salen})(N-\mathrm{mGly})\left(\mathrm{Tf}_{2} \mathrm{~N}\right)\right]$ at $600 \mathrm{~nm}\left(\varepsilon_{\mathrm{com} 2,600}\right)$ were determined as follows. At the equilibrium state, eq. 14 and 16 in the manuscript can be rewritten as eq. S1 and S2, respectively.

For $\left[\mathrm{P}_{\text {nnnm }}\right]_{2}\left[\mathrm{Co}(\right.$ salen $\left.)(N-\text { mGly })_{2}\right]$,

$$
A_{600, \mathrm{eq}}=\varepsilon_{\mathrm{MCIL}, 600}\left(C_{\mathrm{MCIL}, 0}-C_{\mathrm{com} 1, \mathrm{eq}}\right)+\varepsilon_{\mathrm{com} 1,600} C_{\text {com } 1, \mathrm{eq}} \cdot
$$

For $\left[\mathrm{P}_{\mathrm{nnnm}}\right]_{2}\left[\mathrm{Co}\right.$ (salen) $\left(N\right.$-mGly) $\left.\left(\mathrm{Tf}_{2} \mathrm{~N}\right)\right]$,

$$
A_{600, \mathrm{eq}}=\varepsilon_{\mathrm{MCl}, 600}\left(C_{\mathrm{MCIL}, 0}-C_{\mathrm{com} 2, \mathrm{eq}}\right)+\varepsilon_{\mathrm{com} 2,600} C_{\text {com2,eq }} \cdot
$$

where $\varepsilon_{\mathrm{MCl}, 600}$ for $\left[\mathrm{P}_{\mathrm{nnnm}}\right]_{2}\left[\mathrm{Co}(\right.$ salen $\left.)(N-\mathrm{mGly})_{2}\right]$ in eq. $\mathrm{S} 1$ and that for $\left[\mathrm{P}_{\mathrm{nnnm}}\right]_{2}[\mathrm{Co}(\mathrm{salen})(N-$ mGly) $\left.\left(\mathrm{Tf}_{2} \mathrm{~N}\right)\right]$ in eq. $\mathrm{S} 2$ were determined as described above. The $A_{600, \text { eq }}$ values for the solutions of each MCIL were experimentally determined using a UV probe. The $C_{\mathrm{MCIL}, 0}$ values were known. In addition, $C_{\mathrm{com} 1, \mathrm{eq}}$ and $C_{\mathrm{com} 2, \mathrm{eq}}$ could be calculated by the following mass balance expression:

$$
C_{\mathrm{com} 1 \text {,eq }} \text { and } C_{\mathrm{com} 2 \text {,eq }}=\frac{P\left(V_{\mathrm{all}}-V_{\mathrm{MeOH}}\right)\left(x_{0}-x_{\mathrm{eq}}\right) / \mathrm{RT}}{V_{\mathrm{MeOH}}} \text {, }
$$

where $V_{\text {all }}\left(\mathrm{m}^{3}\right)$ is the volume of the three-neck flask $\left(2.88 \times 10^{-4} \mathrm{~m}^{3}\right) ; V_{\mathrm{MeOH}}\left(\mathrm{m}^{3}\right)$, the volume of methanol in the flask $\left(8.00 \times 10^{-5} \mathrm{~m}^{3}\right) ; P(\mathrm{~Pa})$, the total pressure of the gas phase in the flask $\left(101.3 \times 10^{3}\right.$ 
$\mathrm{Pa}) ; \mathrm{R}(\mathrm{J} /(\mathrm{mol} \mathrm{K}))$, the gas constant; $T(\mathrm{~K})$, the temperature $(298 \mathrm{~K}) ; x_{0}(-)$, the molar fraction of $\mathrm{O}_{2}$ in the gas phase prior to the reaction; and $x_{\mathrm{eq}}(-)$, the molar fraction of $\mathrm{O}_{2}$ in the gas phase at the equilibrium state. Thus, $\varepsilon_{\mathrm{com} 1,600}$ and $\varepsilon_{\mathrm{com} 2,600}$ could be determined from eq. S1 and S2, respectively.

The experimental procedure was the same as that mentioned in 2.3. $x_{0}$ and $x_{\mathrm{eq}}$ were measured using a gas chromatograph (VARIAN $\mu$ GC 490-GC, column: Molsieve 5A, $10 \mathrm{~m}$ ).

All the molar absorption coefficients determined in this study are listed in Table S2.
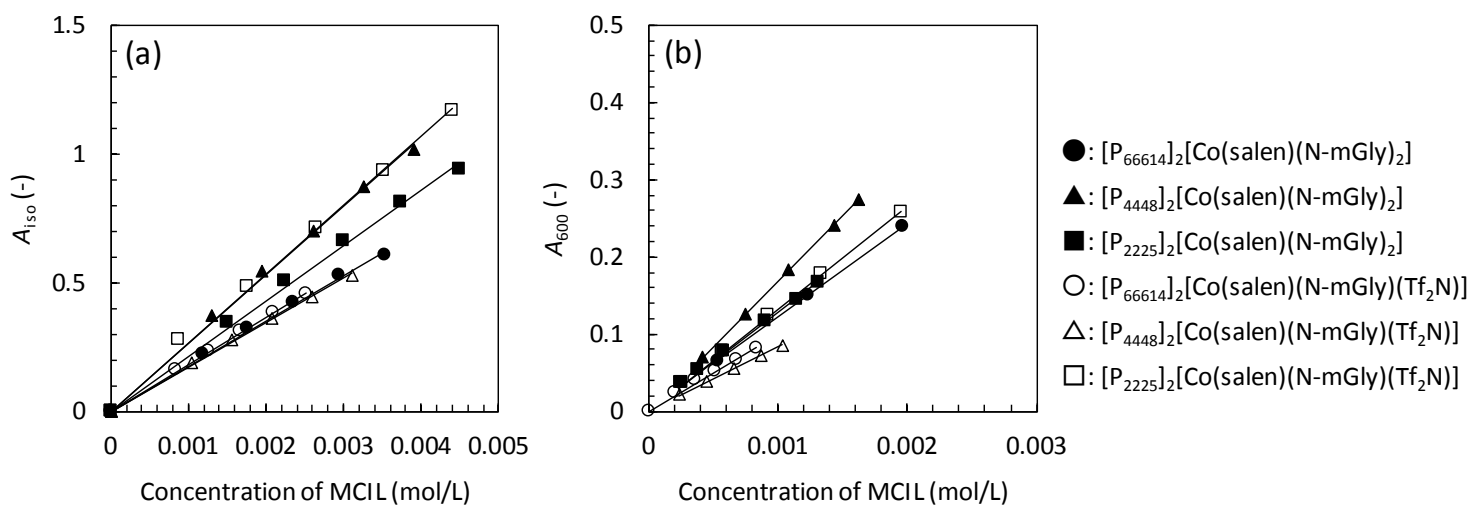

Figure S8. Calibration curves of each MCIL at (a) each isosbestic point and (b) $600 \mathrm{~nm}$. 
Table S2. Molar absorption coefficients $\left(\mathrm{dm}^{3} /(\mathrm{mol} \cdot \mathrm{cm})\right)$ of the MCILs at the isosbestic points and at $600 \mathrm{~nm}$, as well as those of com1 and com2 at $600 \mathrm{~nm}$.

\begin{tabular}{c|ccc|ccc}
\hline & \multicolumn{2}{|c|}{$\left[\mathrm{P}_{\mathrm{nnnm}}\right]_{2}\left[\mathrm{Co}(\mathrm{salen})(\mathrm{N}-\mathrm{mGly})_{2}\right]$} & \multicolumn{3}{c}{$\left[\mathrm{P}_{\mathrm{nnnm}}\right]_{2}\left[\mathrm{Co}(\right.$ salen $\left.)(\mathrm{N}-\mathrm{mGly})\left(\mathrm{Tf}_{2} \mathrm{~N}\right)\right]$} \\
& $\mathrm{P}_{66614}$ & $\mathrm{P}_{4448}$ & $\mathrm{P}_{2225}$ & $\mathrm{P}_{66614}$ & $\mathrm{P}_{4448}$ & $\mathrm{P}_{2225}$ \\
\hline$\varepsilon_{\mathrm{MCIL}, \mathrm{iso}}$ & 176.1 & 266.5 & 215.5 & 182.6 & 172.4 & 267.3 \\
$\varepsilon_{\mathrm{MCIL}, 600}$ & 123.5 & 192.7 & 128.1 & 98.38 & 83.30 & 132.4 \\
$\varepsilon_{\text {com1,600 }}$ & 156.8 & 244.6 & 195.6 & - & - & - \\
$\varepsilon_{\text {com2,600 }}$ & - & - & - & 348.5 & 364.4 & 402.8 \\
\hline
\end{tabular}


(8) $\mathrm{O}_{2}$ absorption isotherms of $\left[\mathrm{P}_{\mathrm{nnnm}}\right]_{2}\left[\mathrm{Co}(\mathrm{salen})(\mathrm{N} \text {-mGly })_{2}\right]$ and

\section{$\left[\mathrm{P}_{\mathrm{nnnm}}\right]_{2}\left[\mathrm{Co}(\right.$ salen $)\left(\mathrm{N}\right.$-mGly)$\left.\left(\mathrm{Tf}_{2} \mathrm{~N}\right)\right]$ with the unit of $\mathrm{mol}-\mathrm{O}_{2} / \mathrm{mol}-\mathrm{MCIL}$}
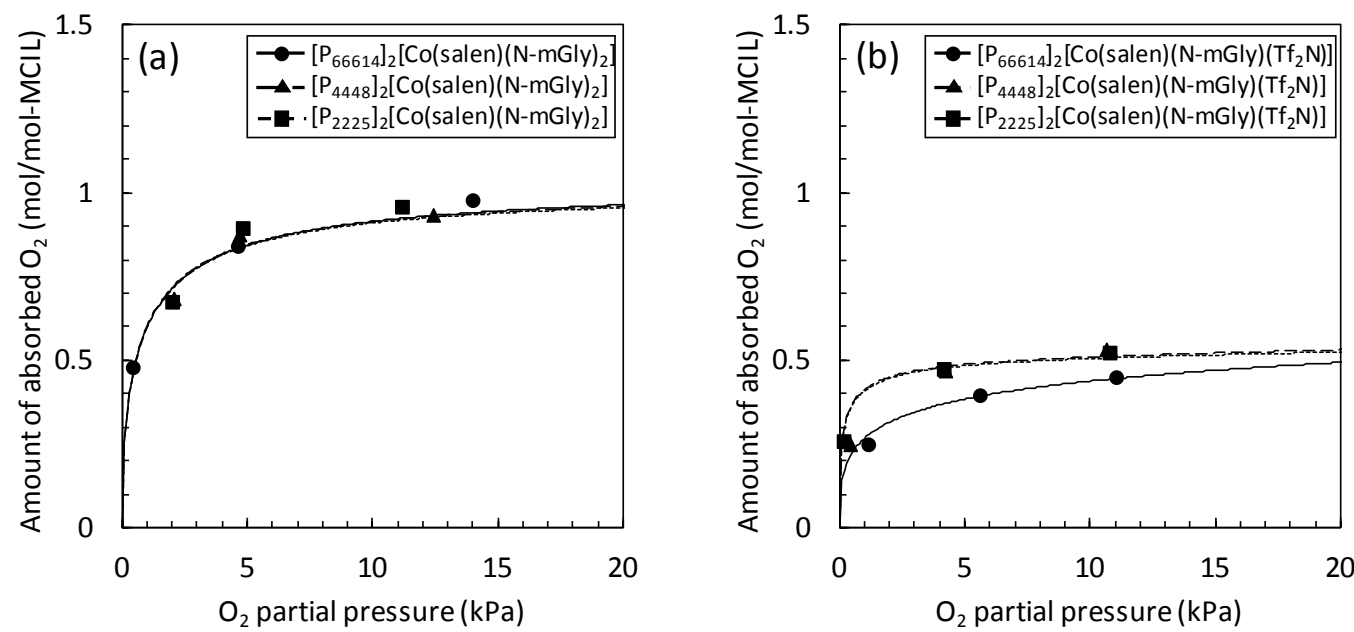

Figure S9. $\mathrm{O}_{2}$ absorption isotherms of (a) $\left[\mathrm{P}_{\mathrm{nnnm}}\right]_{2}\left[\mathrm{Co}(\right.$ salen $\left.)(N-\mathrm{mGly})_{2}\right]$ and (b) $\left[\mathrm{P}_{\mathrm{nnnm}}\right]_{2}[\mathrm{Co}($ salen $)(N-$

mGly) $\left.\left(\mathrm{Tf}_{2} \mathrm{~N}\right)\right]$ at $303 \mathrm{~K}$. The unit of the absorption amount is mol/mol-MCIL. 


\section{References}

(1) Tsunashima, K.; Sugiya, M. Physical and Electrochemical Properties of Low-Viscosity Phosphonium Ionic Liquids as Potential Electrolytes. Electrochem. commun. 2007, 9 (9), 2353-2358.

(2) Matsuoka, A.; Kamio, E.; Mochida, T.; Matsuyama, H. Facilitated $\mathrm{O}_{2}$ transport Membrane Containing Co(II)-Salen Complex-Based Ionic Liquid as $\mathrm{O}_{2}$ carrier. J. Memb. Sci. 2017, $541,393-402$. 